gouty diathesis, either hereditary or acquired, have previously remained free from the more ordinary attacks of this disorder. Its occurrence is of ten assigned to catching cold, getting wet, or sitring upon damp seats. Like gout acutely affecting the great toe, the attack usually comes on at night, the patient experiencing severe pain, which he refers to the perineum, and not unfrequently likens to a hot cork. Though painful, the desire to micturate is irresistible, and is accompanied with spasms, which often render any attempt to retain urine, even while the patient is getting out of bed, almost impossible. Sympathetic pain is at the same time experienced in the groin, or in one or both testicles, rendering the latter extremely seusitive to the touch. Exploration of the rectum with the finger-a necessary examination, which is sometimes so painful as to call for an anæsthetic-shows the prostate to be both tense and teader. During the day the symptoms generally abate, to recur at night. Like the analogous manifestation in the great toe, these acute prostatic attacks are not usually of long duration, as they merge into a chronic form, which will presently be noticed. The urine is loaded with lithates, and is invari ably of an acid and irritating character. After an acute attack the prostate is often left excessively sensitive, and this is a point worthy of special consideration. After an acute attack of gout in the foot the limb is tender, and the person is more or less lame. So with the prostate: it remains sensitive, and the patient dreads to call forth sufficient muscular force to completely empty his bladder. In fact, he lets his urine dribble off voluntarily, and retains a portion of it, so as to form a sort of water-bed behind his prostate. In this way he wards off from his sensitive gland the last and most painful efforts of each act of micturition. Watch a patient, with a prostate tender from gout, pass water, and the manner in which he cautiously eases off the pressure as the act is about to close is very significant. I have eatisfied myself on several occasions that a degree of retention was thus caused by passing a rubber catheter and removing an ounce or so of urine, when it was believed by the patient that he had emptied his bladder.

It is generally conceded that an hypertrophied prostate which causes nrine to be constantly retained within the bladder is a condition favouring the formation of stone. I have thus endeavoured to show that the urine of the gouty is not nnfrequently submitted to similar conditions, but under different circumstances. May not this consideration explain why the inorganic elements of the urine of one gouty person concrete, whilst in another they do not? Is the shortness and dilatability of the female urethra sufficient to explain the rarity of stone in women, even in those of a markedly gouty diathesis?

In the treatment of acute prostatic gout there are one or two points to which prominence is to be given. In the first place it is always associated with a highly acid condition of the urine, and with an excess of urates as well as of uric acid. The administration of alkalies under these circumstances can hardly be regarded other than as a natural expedient. It has been stated that the neutralisation of these urine-salts by the alkali is little else than masking the disorder, as the cause of it still remains untouched. Bat there is a mechanical aspest to this question which must not be passed by entirely without notice. One effect of the administration of alkalies upon such urine is not only attended with a marked disappearance of the urate salts from the urine, but careful mieroscopical ohservation has shown that the use of alkalies is frequently followed by a change in crystalline form, which is of considerable advantage to the patient, though he may still continue to void urates. When the degree of vesical and urethral irritation was intense, I have seen all this disappear coincident with a change in the crystalline form, being brought ahout by some artificial means. It is interesting to no: ice the relation the mucus that is deposited in the urine holds to the kind and quantity of the crystalline forms existing in health as well as in disease in this excretion. Some crystals of uric-acid salts, for example, excite an immense discharge of this mucus. Such salts seem to act uprin the urin rry apparatus much in the same way as a foreign bodv in the eye stimulates a flow of the natural secretion, and readers it inordinate so long as the irritant remains there. Can it be dnubted that the means we possess of influencing the urinary mucus through changes in the urine salts we are capable of artificially effecting are not important ones in relation to the subject of stone formation? Does not such a consideration take us one step further back in treating calculous disorders, or the tendency thereto, by bringing them distiactly within the scope of medicines rather than of machines?

The chronic form of the disorder, where the prostate remains tender for a cousiderable period, or until it is relieved by treatment, requires careful cousideration, as it is a far more frequent cause of residual urine than is generally supposed. Occurring, as it often does, at a period of life when byper. trophy of the gland usually takes place, the demonstration by the catheter that the bladder does not empty itself is $a$ circumstance which is sometimes received and acted upon as conclusive evidence that the time has arrived when what Sir Andrew Clark has aptly spoken of as "the catheter life" should commence. There is this important difference, however, between the residual urine of a sacculated bladder in connexion with a large prostate and that dependent on a gland which is sensitive and merely temporarily enlarged the former is benefited by catheterism, the latter is aggravated by it. The former is comparatively uninfluenced by medicines, whilst the gouty prostate which interferes with the complete emptying of the bladder is speedily relieved by those measures which belong to the department of the phy. sician rather than of the surgeon. Where the urine is rendered alkaline in the bladder by circumstances which bring about its decomposition, it is not difficult to understand how a phosphatic stone may be the result. In the view I have urged, relating to another reason for residual urine, is to be found a vesical cause for the collection and aggregation of those materials which tne urine of the gouty furnish. It has been observed by Dr. Ord, "Two-thirds of all urinary calculi are in bulk composed of or start from concretions of uric acid.

The symptoms of chronic gouty prostatitis are ofter anomalous and difficult to sum up; they may be briefly enumerated as urine habitually loaded with uric acid and urates, unnatural sensitiveness of the prostate to the touch, or even to pressure applied to the perineal region, and the presence of uncomfortable sensations referred to the reck of the bladder, as if there was a swelling, or the viscus was not emptied, the latter sensation being practically well founded. The treatment of the affection resolves itself into the employment of those general measures appropriate to the gouty diathesis, which it is not necessary for me to refer to. Iodide of potassium internally, and a mild form of counter-irritation to the perineum, will often be found very advantageous in removing prostatic tenderness. Lastly, this is a class of disorders which is often largely benefited by some spas where the diathesis is corrected by suitable diet and waters. In our own country I have found Buxton of very great service; whilst abroad there are many wateringplaces which such persons may visit with advantage. It is not always easy to recommend suitable drinks for these cases. I have found the Giesshübler Sauerbrunnen a very pleasant beverage; as imported into this country $I$ ear endorse Dr. Kraus' ${ }^{2}$ recommendation of it as "a very pleasant and refreshing drink, which invigorates the nervors.s system, removes acidity of the stomach, gently stimulates the action of the bowels, and causes a copious flow of urine thus combining the qualities of a good drinking water with those of a mild curative agent." It mixes well with red wine. Liverpool.

\section{AN UNUSUAL CASE OF CLEFT PALATE.}

\section{BY A. ERNEST MAYLARD, B.S. LOND.,}

EXTRA DISPEASARY SURGEON TO THE WESTERN INFIRMARY, GLASGOT, CLINICAL ASSISTANT TO THE PROFESSOR OF SURGERY AT TII UNIVERSTTY OF GLASGOW.

THE following case was admitted into the Western Inf $\mathrm{r}$ mary of Glasgow, under the charge of Professor Macleod, to whom $\mathrm{I}$ am indebted for permission to publish it.

The child, a male, aged four months, was brought to the infirmary with what appeared at first sight a simple uncomplicated case of left harelip, but on closer examination the following unusual condition of parts was seen. Immediately behind the cleft in the lip was a division in the alveolus, and extending back directly from this with. no deviation towards the middle line, a narrow fissure which widened out posteriorly in to a well-marked interval. On the

1 The Influence of Colloids upon Crystalline Form, p. 60.

2 The mineral water at Carlsbad. 
opposite side, at, the same distance from the middle line, and running parallel with it, was an interval resembling precisely the posterior portion of the left cleft. The part between the two clefts was about one-fourth of an inch in width, and maintained this dimension in its course backwards, when, becoming slightly arched, it was continued into the posterior wall of the pharynx. On digital examination this central partition appeared to be bony in structure and uninterruptedly connected with the back of the pharyox, while both the clefts passed into the hard palare. Stil further it was found that by the aid of a bent probe it was impossible to pass from one side to the other above the arch, the sensation being that of a bony septum completely separating the two sides of the pharynx above. The accompanying sketch, which was kindly taken for me by the ward clerk, Mr. Wall $a c e$, will perhaps help to elucidate the description. $a$ indicates the central partition passing backwards to the posterior wall of
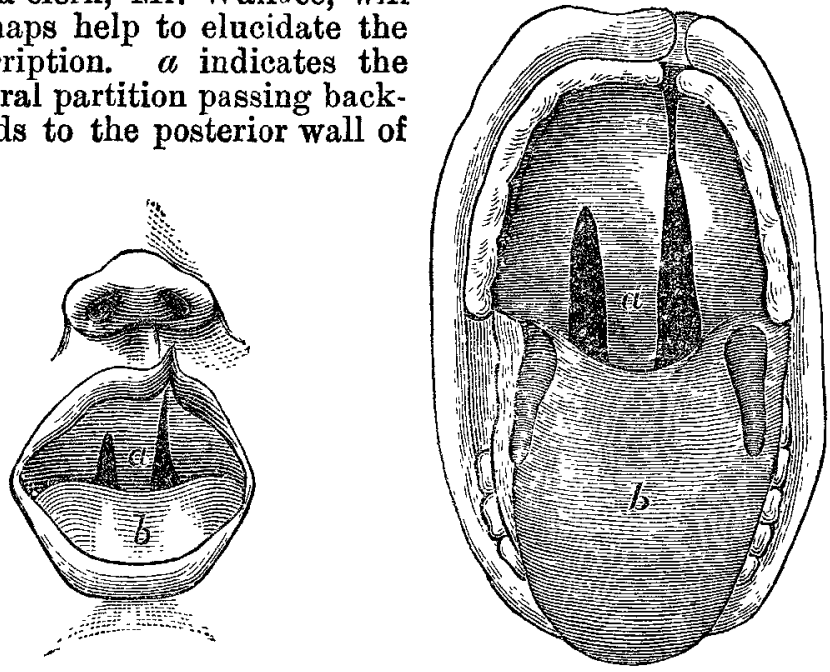

the pharynx, having on the left the long cleft continuous with the harelip, and on the right the short cleft; $b$, the tongue. Remarks.-The foregoing case presents, I think, features of unusual interest, both from its apparent uniqueness and from the peculiar developmental process $\mathrm{ky}$ which it must have been produced. So far as I have been able to examine into the literature of the subject, I can find no parallel case on record. Most authors, in alluding to the posterior cleft of the palate, speak of it as always occurring in the middle line-an assertion no doubt depending as much upon the result of their experience as upon the deduction that in the normal process of development only such a median fissure can occur. Giraldès, ${ }^{1}$ in his work on the Surgical Diseases of Children, figures a case in which there appears to be a double posterior cleft, but there is no allusion to it in the context. That the malformation in the present case is the result of mal-development, and not of intra-uterine disease, there can, I think, be no doubt, and as such I shall venture to offer an explanation. To do so it will be necessary first to refer to the way in which the usual clefts are produced. It will be remembered that in early fotal life, at a time when the face begins to be formed, there descends from the frontal region a process known as the fronto-nasal plate, from which is developed at its upper part the integument and columella of the nose, and at its lower the middle portion of the upper lip. At the same time, there proceeds from above and externally on either side another process, the superior maxillary, which, winding round and extending towards the middle line, unites with the fronto-nasal plate to form the entire upper lip. Thus any failure of union between these two processes, either on one or both sides, will explain the formation of a single or double barelip; and upon the extent of that union the completeness or incompleteness of the fissure into the nostril. A harelip, then, must always be on one side of the median line. ${ }^{2}$ With regard to the cleft of the alveolus and palate, which more immediately has reference to the present case, it will be remembered that at the same time in which the above process is proceeding there is also a deeper development taking place by which the walls of the nares are being formed, and the nasal cavity cut off from the buccal. The process may be briefly stated thus. Extending forwards

I Lecons sur les Maladies Chirurgicales des Enfants, p. 151.

Rokitansky alludes to cases of median fissure, and there is a specimen in the Royal College of Surgeons showing the same. The explanation appears to be in the non-dovelopment of the so incisin and maxillary processes. beneath the primitive brain structure from the mass of blastema which surrounds the termination of the noto. chord, and which in the fully developed skull becomes the posterior part of the body of the sphenoid, are two processes known as the trabecula cranii. These, after dividing so as to enclose a space which eventually becomes the pituitary fossa unite again and passing forward descend in the middle line immediately behind the fronto-nasal plate. From their termination is developed the intermaxillary bone or os incisivum, and from the upper coalesced portion descends a thin plate to form the matrix of the vomer, the perpendicular plate of the ethmoid and triangular cartilage of the nose-the nasal septum. Concurrently with this is the descent on each side of a plate known as the pterygo-palatine, which passing inwards and forwards towards the middle line, unite in front with the os incisivum and behind with each other, thus shutting off the nasal from the buccal cavity, and containing the matrix of the palate, pterygoid, and part of the superior maxillary bones. It will now be easily seen that any failure in this the normal process of development, while it will produce a double cleft in front (i e., one on either side of the os incisivum), can only produce a single median cleft behind. In a case, then, of complicated harelip, in which the cleft runs completely through the alveolns, hard and soft palate, the line of fissure will commence in front on either side of the median line, course obliquely inwards after having passed through the alveolus, and then directly backwards through the centre of the palate. In the present case it will be noticed that the left cleft commences on one side of the middle line, and then without any internal deviation continues as a complete fissure through the palate. Such a fissure, without any other malformation, could undoubtedly be explained by excessive growth on one side with diminished growth on the opposite, just as not unlikely the high vaulted palate is produced by overgrowth on both sides. No such explanation, however, is tenable in the present case; and one must seek, I think, for the cause of the deformity in an abnormal deviation of the developmental process rather than in those more natural courses by which the usual malformations are produced.

I venture then to suggest the following explanation. Instead of the notochord ceasing as it usually does beneath the pituitary fossa, it has reached farther forward; and the encircling blastema instead of simply forming the matrix of the basi-occipital and basi-sphenoid has extended with it and become united with the plate descending from the coalesced trabeculæ cranii, which forms the nasal septum. Thus is produced the complete division of the upper part of the pharynx into two lateral halves. Did it not appear from the thickness of this osseous arch that it must be developed from the same blastema as gives origin to the basilar part of the occipital and posterior portion of the body of the sphenoid, homology would suggest a condition of parts like that found in amphibians and some kinds of fishes. In tbem there exists a distinct splint-like membrane bone, the parasphenoid, which extends from the basi-occipital to the presphenoidal reoions, similarly dividing the upper part of the pharynx into two. Should the former be the true ex. planation, it becomes an interesting question as to how the future development of the face is likely to be affected. What influence will this thick bridge of bone passing from the basilar part of the occipital forwards to the septum nasi and superior dental arch have on those various changes in the development of the nose and superior maxilla which are brought about by the subsequent expansion of the sphenoidal sinuses. It is to be hoped for the patient's sake that the future somewhat unprepossessing underhung appearance which the foregoing arguments would suggest as a prognosis, may be compensated for or prevented by other means than those one is at present able to foresee. Glasgow.

AT the meeting of the St. Georges-in-the-East Board of Guardians on the $16 \mathrm{th}$ inst, a letter was read from the Local Government Board respecting the alleged deatho an inmate from oakum-picking. The communication stated that no sufficient evidence was brought forward at the ofticial inquiry to connect the man's death with his employment at the very slight task of work allotted to him in the oakum. shed. The Local Government Board, however, censure Dr. Deacon, the assistant medical officer, for the delay in attend. ing to the man. 